\title{
Rehabilitation by Chemical Treatment for Sand Media of Rapid Sand Filtration units for Sangli City
}

\author{
Mr. Gopal M. Bhosale ${ }^{1}$, Prof. V. D. Salkar ${ }^{2}$ \\ M. Tech student,(Civil-Environmental Engineering), Walchand College of Engineering, Sangli. \\ Associate professor, Dept. of Civil Engineering, Walchand College of Engineering, Sangli.
}

\begin{abstract}
Rapid sand filtration is key unit process in water treatment. This process is a combination of normal cycle i.e. filtration followed by backwashing. Backwash is up flow cycle for cleaning of clogged media, air scour is used to remove deposit from filter media by vigorous agitation, and wash water is used to remove deposits from the filter bed. The combined action of air and water should return the media quickly to its original perfectly clean state for the next cycle.

It is seen that, after backwashing media does not come in clean state due to poor backwashing and next cycle starts with trapped particles. This leads to accumulation of deposits on filter media which results into deterioration of media and reduces filter run and gives poor water quality. After some years these deposits turns into hard deposits which are very difficult to remove. This paper focuses on the methods for sampling of sand media, characterization and chemical treatments on media to clean and reuse it instead of replacing old media with new one.
\end{abstract}

Keywords: Specific deposit, Filter media, characterization.

\section{Introduction}

Rapid sand filtration is a vital unit process in the water purification process. It captures and removes coagulated and flocculated matter and other suspended matter not removed during the earlier treatment processes. The pores in the filter bed slowly become clogged with each filter run and the media progressively collects deposit through the continuous use. During normal operations cleaning is initiated by excessive head loss, deterioration in filtrate quality or when the predetermined time for a filter run has elapsed. For the study three treatment plants in Sangli city were selected. Sand media cleanliness was determined by collecting samples after backwashing, which gives specific deposit present on it after backwashing. In studied treatment plants filtration media is used for years without any treatment. According to BM Brouckaert et al., (2007), it is expected that treatment plants' managers should replace or chemically clean their filter media every year or two if they do not use auxiliary wash. In Sangli city there is no provision of auxiliary backwash.

\section{Methodology}

\subsection{Methodology Adopted for sampling of sand media:}

There are no studies for Sangli city revealing filter media cleanliness and performance of filter units. Main important task in this study is collection of sand media sample. Sand sample collection is done manually by dig and draw method. The other method of sample collection is core drilling method (Haarhoff et al, 2006). In which a core sampler of diameter $35 \mathrm{~mm}$ is inserted in sand media up to required depth and removed that core sampler without disturbing it. But as sand is cohesion less material removal of sampler with sand sample is difficult task. So, this method is not implemented. After backwashing filter bed was kept empty for percolating water through then sample of sand was collected. Sample was collected from the depth of $15 \mathrm{~cm}$ of surface to exclude upper region of media where most of the particles are trapped because our intention is checking overall deterioration of sand media. Collecting sample from upper portion of media may misguide us.

For getting representative sample, samples from four corners and at the centre of filter bed were collected and mixed.

\subsection{Laboratory Experimentation.}

Standard methods are used for laboratory experimentation. Samples are brought to laboratory for analysis of various parameters like Specific gravity, acid solubility, uniformity coefficient, silica content along with turbidity of sand wash water etc. Specific gravity and turbidity of sand wash water gives idea about cleanliness of sand media and presence of specific deposit on sand.

According to Clements (2004) due to ineffective backwashing specific deposits accumulate on sand media and become difficult to remove. As days pass these deposits grows and becomes a thick layer which is having low specific gravity with increased size. The sand particles having such layer of deposit becomes lighter and escapes out from filter unit during backwashing which results in loss of media. Turbidity of sand wash water 
gives specific deposits present on sand. For this purpose Haarhoff et al. (2006) have given different methods like cylinder inversion method, magnetic stirrer method, hand swirl method, jar test, violent shake method etc. In this study cylinder inversion method is used.

\subsubsection{Characterization of sand media sample}

Characterisation of sand media is done for following parameters.

- $\quad$ Sp. Gravity $(\mathrm{kg} / \mathrm{m} 3)$

- Turbidity of sand wash water sample (NTU)

- Acid loss (\%)

- U.C.

- $\quad$ Silica Content $(\%)$

For specific gravity pycnometer is used. Turbidity of sand wash water sample is measured with the help of turbidity meter. For acid loss $10 \%$ HCL solution is used. Uniformity coefficient is calculated with the help of sieve analysis. For silica content concentrated HCL solution is used.

Haarhoff (2004) have discussed that, the American Water Works Association (AWWA) also suggested that the routine measure of media grain cleanliness would result in early detection of the potential for serious problems within filters and, thereby, allow for evasive action to be taken to arrest such problems. This routine measure took place in the form of a .floc retention test. This test is simply described as taking approximately $50 \mathrm{~g}$ of filter sand, adding $100 \mathrm{ml}$ of water, shaking it vigorously and decanting the resultant suspension into a beaker. After five repetitions, the turbidity of the suspension is measured, multiplied by two and reported as NTU (nephelometric turbidity units) $/ 100 \mathrm{~g}$ of sand. The turbidity, according to AWWA, allows the media to be assigned to one of the following four categories:

- A value of 30 to $60 \mathrm{NTU}$ (threshold A) indicates a clean bed

- 60 to $120 \mathrm{NTU}$ (threshold B) indicates a slightly clogged bed

- 120 to $300 \mathrm{NTU}$ (threshold C) indicates a clogged filter with mudball formation potential

- Above 300 NTU indicate a serious problem with highly probable mudball formation

Characterization of sand sample media of different water treatment plants is done for three selected treatment plants in Sangli city of Maharashtra as per study area selected. The results are shown in following table for different parameters.

Table 1: Characterization of sand media sample

\begin{tabular}{|c|c|c|c|c|c|}
\hline Bed No. & $\begin{array}{c}\text { Sp. Gravity } \\
\left(\mathrm{kg} / \mathrm{m}^{3}\right)\end{array}$ & $\begin{array}{c}\text { Turbidity of } \\
\text { sand wash water } \\
\text { sample (NTU) }\end{array}$ & $\begin{array}{c}\text { Acid loss } \\
(\%)\end{array}$ & U.C. & $\begin{array}{c}\text { Silica Content } \\
(\%)\end{array}$ \\
\hline \multicolumn{6}{|c|}{ Miraj Water Treatment Plant } \\
\hline Bed No. 1 & 2.5 & 1098 & 4 & 1.76 & 96 \\
\hline Bed No. 2 & 2.64 & 986 & 3.8 & 1.84 & 97.5 \\
\hline Bed No. 3 & 2.64 & 1156 & 3 & 2.03 & 97.8 \\
\hline Bed No. 4 & 2.7 & 1044 & 4.1 & 2.11 & 98 \\
\hline Bed No. 5 & 2.56 & 998 & 2.7 & 2.4 & 92.6 \\
\hline \multicolumn{6}{|c|}{ Hirabag Water Treatment Plant } \\
\hline Bed No. 1 & 2.44 & 996 & 4.3 & 1.75 & 97.4 \\
\hline Bed No. 2 & 2.67 & 1024 & 4.7 & 1.94 & 93.2 \\
\hline Bed No. 3 & 2.67 & 866 & 3.2 & 1.74 & 93.6 \\
\hline Bed No. & $\begin{array}{c}\text { Sp. Gravity } \\
\left(\mathrm{kg} / \mathrm{m}^{3}\right)\end{array}$ & $\begin{array}{c}\text { Turbidity of } \\
\text { sand wash water } \\
\text { sample (NTU) }\end{array}$ & $\begin{array}{c}\text { Acid loss } \\
(\%)\end{array}$ & U.C. & $\begin{array}{c}\text { Silica Content } \\
(\%)\end{array}$ \\
\hline \multicolumn{6}{|c|}{ Malbunglow Water Treatment Plant } \\
\hline Bed No. 1 & 2.35 & 1102 & 3.4 & 2.67 & 92.4 \\
\hline Bed No. 2 & 2.31 & 1080 & 2.5 & 2.07 & 96.8 \\
\hline Bed No. 3 & 2.61 & 876 & 3.1 & 2.30 & 95.7 \\
\hline Bed No. 4 & 2.4 & 864 & 3.8 & 2.23 & 94.1 \\
\hline Limits & 2.65 & -- & $5 \%$ & 1.3-1.7 & $\geq 91$ \\
\hline
\end{tabular}

\subsubsection{Rehabilitation of sand media}

Rehabilitation of sand media is simply treating used or soiled sand media and reuse for filtration purpose. There are different methods for rehabilitation of sand media. Some methods are in-situ and some are ex-situ. Ex-situ methods are mainly physical or mechanical while in- situ methods are chemical methods. There are two Ex-situ methods like removing soiled media and replace it with new media. Another method is removing soiled media treat it and refill. These methods are time consuming and costly.

The easiest and most cost effective method involves in situ chemical cleaning of filter media (Underwood, 1993). In chemical treatment different biocides available are chlorine, ozone, peroxide; aluminium 
compounds (Quats), formaldehyde. Chlorine is least expensive and most effective of all chemical biocides. Combination of $\mathrm{HCL}$ acid and $\mathrm{NaOH}$ also gives good results.

\subsubsection{Chemical Treatment}

In chemical treatment 5 methods are studied for comparison, the method which removes more specific deposits is confirmed as most efficient method. Sand media sample of $20 \mathrm{~g}$ is taken for all methods as initial weight. Final weight of sample is taken after treatment and compared with initial weight.

- $10 \%$ HCL solution

- Hot water

- $5 \% \mathrm{HCL}+5 \% \mathrm{NaOH}$

- $10 \%$ HCL 1 hr soaking

- $5 \% \mathrm{HCL}+5 \% \mathrm{NaOH} 1 \mathrm{hr}$ soaking

Above 5 combinations are compared for effectiveness.

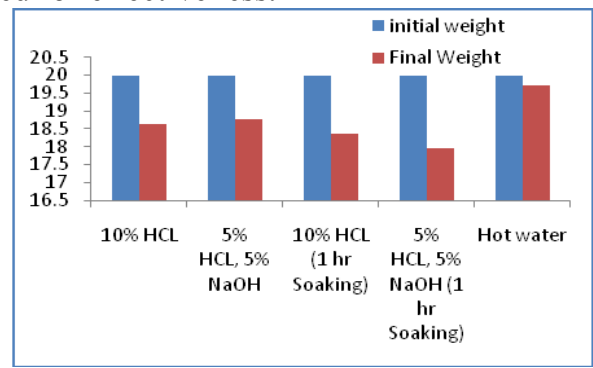

Fig 1: Comparison of different chemical treatments on media

Above study of different chemical combinations shows that, $5 \% \mathrm{HCL}$ with $5 \% \mathrm{NaOH}$ gives better specific deposit removal from sand media. It is adopted for further study as most efficient combination for specific deposit removal.

A pilot filter set up is equipped to evaluate performance of rehabilitated sand media and soiled media.

\section{Experimental Set-Up}

Pilot rapid sand filter set up is designed to evaluate performance evaluation of rehabilitated filter media against soiled filter media. As per the literature review ("Water treatment Principles and design", MWH publication 3rd edition 2012) the design for set-up was done. In general the diameter of the column should be at least fifty times the diameter of the media (John S. Lang et al., 1993). Filter column of diameter $100 \mathrm{~mm}$ is installed with $600 \mathrm{~mm}$ sand depth, $1.8 \mathrm{~m}$ water head and level tube arrangement for measuring head loss during filter run.

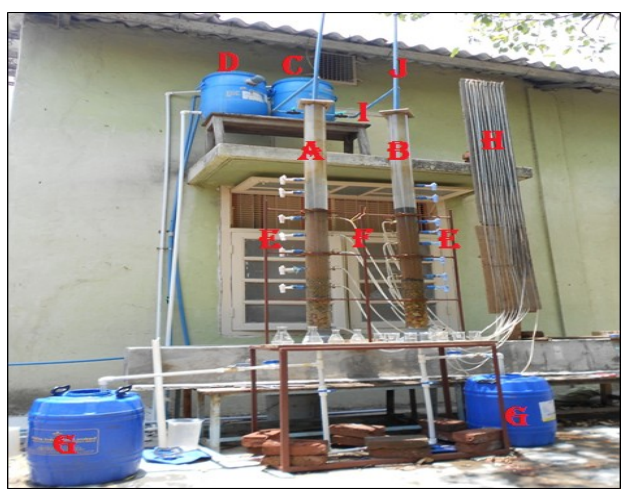

Fig. 2 Experimental set up for Rapid sand filter unit

\begin{tabular}{|c|c|c|c|}
\hline & Rapid sand filter column & B- & Rehabilitated Rapid sand filter \\
\hline C- & Coagulated turbid water & D- & Clear water backwashing \\
\hline E- & Sampling port & $\mathrm{F}-$ & Headloss port \\
\hline G- & Filtered water tank & $\mathrm{H}-$ & Pitot tube \\
\hline I- & Inlet pipe & J- & Vent pipe \\
\hline
\end{tabular}

\subsection{Performance evaluation of pilot filter set up}

Performance evaluation is studied with pilot set up in which parameters like filter run; turbidity removal efficiency and headloss developed are focused. Following figures shows results for different filter 
runs. Filter run for rehabilitated sand media is greater than filter unit with soiled media particles. For this study filtration rate range was decided in the range of conventional rapid sand filters which is $6 \mathrm{~m} / \mathrm{hr}-12 \mathrm{~m} / \mathrm{hr}$ generally. It can vary up to $15 \mathrm{~m} / \mathrm{hr}$ for some cases. Turbidity removal efficiency is measured in terms of turbidity of influent and effluent.

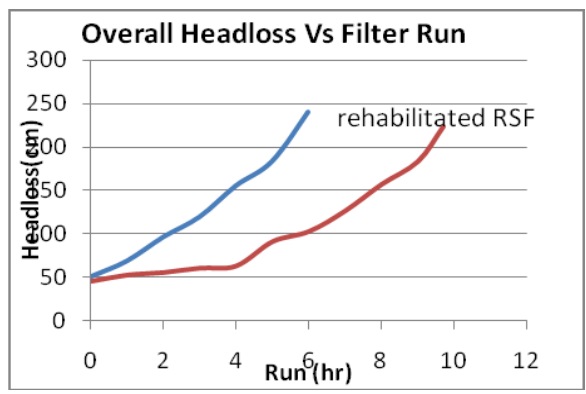

Fig. 3Filter run 1 , for $7.6 \mathrm{~m} / \mathrm{hr}$ filtration rate

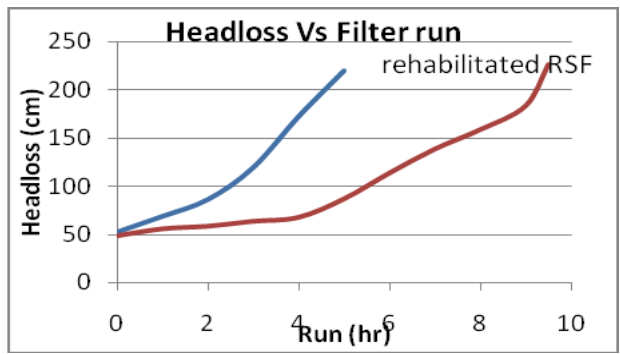

Fig.4 Filter run 2 , for $7.6 \mathrm{~m} / \mathrm{hr}$ filtration rate

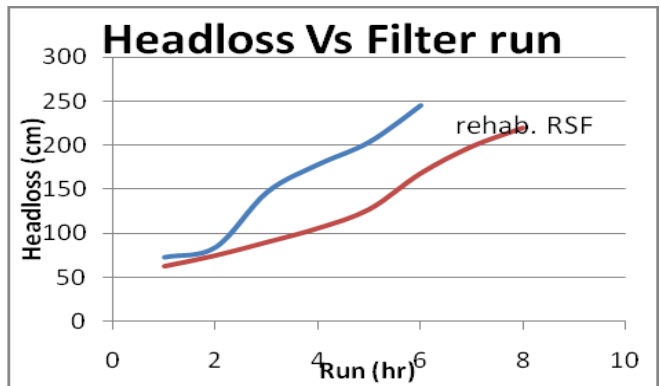

Fig.5 Filter run 3 , for $7.6 \mathrm{~m} / \mathrm{hr}$ filtration rate

Performance of both media from figures 3, 4 and 5 gives that, rehabilitated sand media gives better filter run with less headloss development. It shows that, rehabilitated sand media particles does not clogs for long time compared with soiled media without rehabilitation.

Also turbidity removal efficiency is studied by comparing initial and turbidity of water sample.

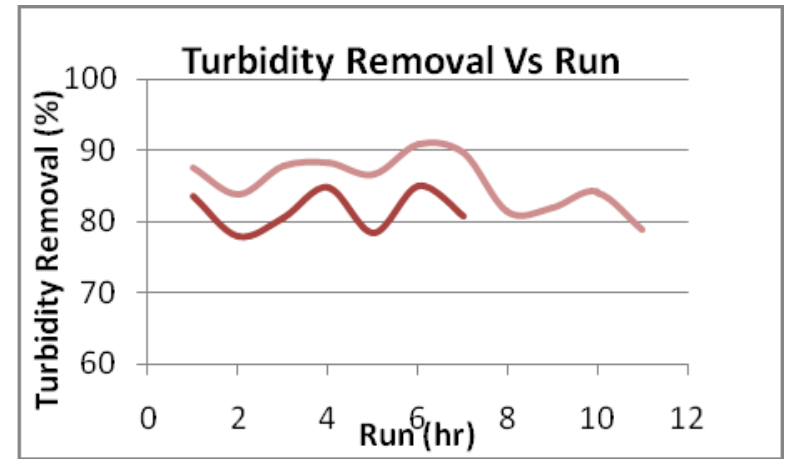

Fig.6 Filter run 1, for $7.6 \mathrm{~m} / \mathrm{hr}$ filtration rate 


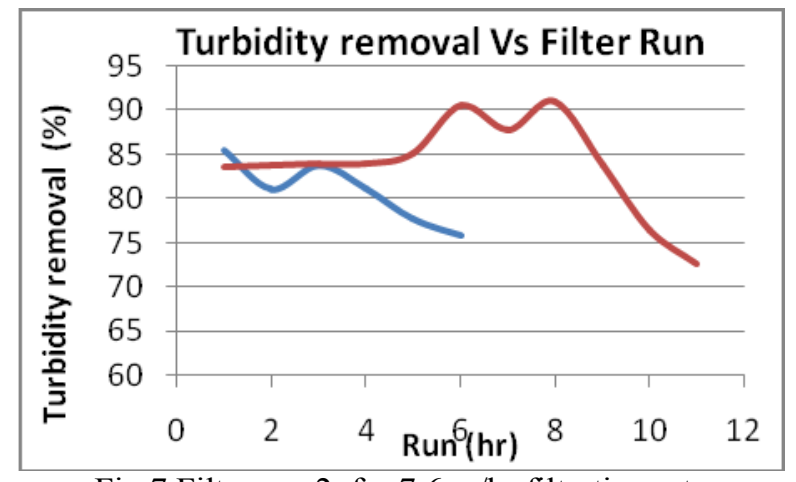

Fig.7 Filter run 2, for $7.6 \mathrm{~m} / \mathrm{hr}$ filtration rate

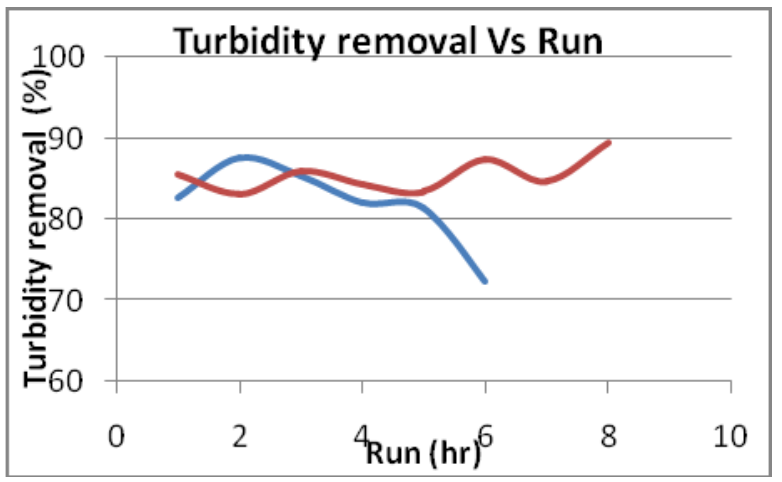

Fig.8 Filter run 3 , for $7.6 \mathrm{~m} / \mathrm{hr}$ filtration rate

From above figures 6,7 and 8 it is clear that, turbidity removal efficiency of soiled filter media diminish earlier than rehabilitated filter media.

\section{Result and discussion}

Characterisation of sand media (Table 1), clears that sand media in water treatment plants in Sangli is excessively dirty. The specific gravity of sand media is reduced upto 2.3 due to presence of specific deposit on media, which results in loss in media during backwash. In design of filter backwash velocity is calculated with specific gravity of sand as 2.65 but actual specific gravity is reduced due to deposits. These particles escapes with backwash water in wash water trough.

Turbidity of sand wash water is also very high which suggests that backwashing in insufficient so large number of particles presents in media. If we compare with AWWA guidelines for media cleanliness, all samples are in catagory of a serious problem with highly probable mudball formation. Uniformity coefficients are also above range which results in increased filtration rate so possibility of short circuiting increases. Silica content and acid loss are in limit.

Out of all 5 treatment methods combination of 5\% HCL solution and 5\% $\mathrm{NaOH}$ solution with $1 \mathrm{hr}$. soaking time removes more specific deposits. Acid content in media can be removed by passing fresh water through media. So there will not be issue of acid content in filtered water when filtration starts with treated media.

\section{Conclusions}

The characterisation of sand media clearly gives idea that sand media is excessively dirty and backwashing is insufficient. Chemical treatment for media is a best option for removing hard deposits and brought sand media in clean state. Combination of $5 \%$ HCL solution with $5 \% \mathrm{NaOH}$ solution is a good combination in specific deposit removal point of view. Rehabilitation allows using same sand media for next few years instead of replacing it with new sand.

\section{References}

[1]. Brouckaert et al.,(2006), "Predicting the efficiency of deposit removal during filter backwash", Water Institute of South Africa (WISA), Biennial Conference, Vol. 32, No. 5, 532-541.

[2]. Clements M. and Haarhoff J. (2004) "Filter media expansion during backwash: The effect of biological activity", Water SA, Vol. 30, No. $5,52-55$.

[3]. Clements M. (2005), "Changes in Mechanical Behaviour of Filter media Due to Biological Growth", Unpublished D. Engg degree thesis, University of Johannesburg. 
[4]. Haarhoff J. and Staden S. J. van (2008), “Assessments and Improvement of Filter Media Cleanliness in Rapid Gravity Sand Filters", Report to the Water Research Commission University of Johannesburg.

[5]. Mota M. H. (2012), "Rehabilitation and Capacity Augmentation of Water Treatment Plant at Malbunglow Sangli", M. Tech thesis Walchand College of Engg. Sangli.

[6]. Staden S. J. van and Haarhoff J. (2003), “A standard test for filter media cleanliness”, Water SA, Vol. 30, No. 1, 81-88.

[7]. Staden S. J. van and Haarhoff J. (2004), "What simple Media Tests Can Tell You about Filter problems and Rehabilitation", Proceedings of the Water Institute of South Africa (WISA), Biennial Conference, 2-6 May 2004 